\title{
Quality of Life of Patients with Metastatic Breast Cancer Treated with Epirubicin and Docetaxel ${ }^{*}$
}

\author{
Jaana Korpela ${ }^{1}$, Pekka Mali ${ }^{1}$, Anne Kaljonen ${ }^{2}$, Eeva Salminen ${ }^{1}$ \\ ${ }^{1}$ Department of Oncology and Radiotherapy, Turku University Hospital, Turku, Finland; ${ }^{2}$ Turku Institute for Child and Youth \\ Research, University of Turku, Turku, Finland. \\ Email: jaana.korpela@utu.fi
}

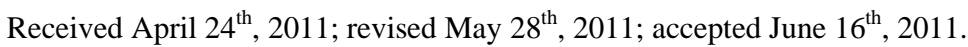

\begin{abstract}
This phase II study assessed the clinical response and short-term quality of life of patients receiving first-line chemotherapy with epirubicin-docetaxel combination for metastatic breast cancer. Thirty-one breast cancer patients were treated with epirubicin (75 mg/m $\mathrm{m}^{2}$ for 15 minutes) followed one hour later by a one-hour infusion of docetaxel (75 $\mathrm{mg} / \mathrm{m}^{2}$ ) q3w. EORTC QLQ-C30 and EORTC QLQ-BR23 forms were filled in at baseline, and at the second and eighth cycle of chemotherapy. The combination of epirubicin and docetaxel provided a high degree of clinical benefit. Clinical response was observed in 17 patients (55\%), including five (16\%) complete responses and 12 (39\%) partial responses. Of responding and stable patients 23 (74\%) maintained the same status for at least six months (clinical benefit). The mean survival time was 40.8 months. During the treatment the emotional functioning improved and the concerns about the future were relieved. Some aspects of quality of life were impaired, with slightly decreased physical and cognitive functioning, distress related to body image and hair loss, and adverse effects of chemotherapy. Overall, the global quality of life was maintained.
\end{abstract}

Keywords: Metastatic Breast Cancer, Chemotherapy, Epirubicin, Docetaxel, Quality of Life

\section{Introduction}

As metastatic breast cancer still remains essentially incurable, the main goals of therapy include treatment of symptoms and maintaining the quality of life, as well as a delay in disease progression and prolongation of overall survival. As women with metastatic breast cancer have a relatively short expected survival time, the impact on quality of life is an important factor to consider when making treatment decisions. The adverse effects of treatment should be kept as low as possible and small gains must be weighed against the severity of adverse effects. Collection of data from formal quality of life instruments can broaden the parameters of benefit beyond response and survival, and can allow more accurate determination of the supportive and ameliorative interventions needed by the patients. Nevertheless, perhaps due to methodological difficulties, many clinical trials in metastatic breast cancer have been published without quality of life data [1].

Chemotherapy is the mainstay of treatment for metastatic breast cancer patients with hormone receptor-

*Supported by the Cancer Society of South-Western Finland (JK). negative disease or with hormone receptor-positive disease which has become resistant to endocrine therapy, or is rapidly progressive and life-threatening. Anthracycline- and taxane- based therapies have shown the highest degree of response in metastatic breast cancer. Taxane-containing regimens are associated with increased overall survival [2]. Relatively few studies have reported the effect of the combination of anthracyclines and taxanes on the quality of life among women treated first-line for metastatic breast cancer [3-8]. Even less is known about the effects of epirubicin and docetaxel combination on the quality of life. To our knowledge previously only Yeo et al. have reported the effects of an epirubicin and docetaxel combination on the quality of life in metastatic breast cancer [9].

Previously, we have reported the efficacy, toxicity and cost of treatment with the combination of epirubicin and docetaxel in metastatic breast cancer [10-12]. This report assessed the short-term quality of life outcome.

\section{Methods}

\subsection{Patients and Treatment}

Originally thirty-eight patients with metastatic breast 
cancer were treated with the combination of epirubicin and docetaxel. In this report only the 35 Finnish-speaking patients were included. Eligibility criteria for the epirubicin-docetaxel study included written informed consent, age 18 - 75 years, ECOG performance status $\leq 2$, white blood cell count $>3000 / \mathrm{mm}^{3}$, platelet count $\geq 130,000$ / $\mathrm{mm}^{3}$, and liver function $<3$ times the normal value. Previous adjuvant treatment with CMF (cyclophos- phamide, methotrexate and 5-fluorouracil) or CEF (cyclo-phosphamide, epirubicin and 5-fluorouracil) was allowed, as were prior hormonal therapy or radiotherapy. Exclusion criteria included brain or leptomeningeal involvement and active infection. The study was conducted according to the ethical standards described in the Helsinki Declaration. The protocol was approved by the Ethical Committee of Turku University Hospital and written informed consent was obtained from the patients.

The patients were treated with epirubicin $\left(75 \mathrm{mg} / \mathrm{m}^{2}\right.$ 15-minute infusion) followed one hour later by docetaxel (75 mg/m², one-hour infusion) every three weeks. The doses were based on earlier studies that have demonstrated the applicable levels without growth factor support $[13,14]$. Mid-cycle counts were taken on day $10-11$. The aim was to give eight cycles to responding/stable patients. The starting dose of $75 \mathrm{mg} / \mathrm{m}^{2}$ for both epirubicin and docetaxel was reduced by $25 \%$ if the patient was hospitalized due to febrile neutropenia, required antibiotics, or developed prolonged neutropenia. Premedication of prednisolone (40 mg) was given orally the night before treatment and continued b.i.d. on days 1 - 3. A prophylactic anti-emetic was given according to routine practice (5HT-blocker prior to chemotherapy infusion).

\subsection{Response}

Response was defined according to WHO criteria after the third cycle and at close of treatment [15]. Clinical benefit was calculated for responding and stable patients maintaining the same status for at least six months. The mean follow-up time was 79.9 months.

\subsection{Quality of Life Evaluations and Statistical Analysis}

Quality of life was assessed with the European Organization for Research and Treatment of Cancer Quality of Life Questionnaire EORTC QLQ-C30 version +3 [16] and the QLQ-BR23 Breast module [17]. The patients filled in the EORTC QLQ-C30 forms at baseline, just before the second and eighth cycle, and three months after the last cycle. EORTC QLQ-C30 raw scores were calculated according to guidelines, yielding a range of 0 - 100. A high score on the functional or global quality of life scale represents a better level of functioning, and a high score on the symptom or item scale represents more symptoms. According to Osoba et al., a difference of 5 to 10 points on a 0 to 100 scale is considered a small clinically significant change, a difference of 10 to 20 points a moderate change, and changes greater than 20 points would be interpreted as large changes in quality of life [18].

The comparisons of quality of life scores at different time points were carried out with analysis of variance for repeated measurements. The analyses were performed using the MIXED procedure (SAS system for Windows XP version 9.1.3 2003) which offers a sophisticated tool for analysis of follow-up data with possible missing data during follow-up (Littell R, Milliken GA, Stroup W, Wolfinger RD. SAS ${ }^{\circledR}$ system for Mixed Models. Cary, NC: SAS Institute, Inc, 1996). P-values less than 0.05 were considered statistically significant. The survival analysis was estimated using the KaplanMeier technique.

\section{Results}

\subsection{Patient Characteristics and Treatment}

Patient characteristics are shown in Table 1. The mean age was 50 years (range 35 - 72 years). The mean ECOG performance status was 1 (range 0 - 2) before chemotherapy. Twenty-seven patients (87\%) received all the planned eight cycles.

\subsection{Response}

Clinical response was achieved by seventeen patients (55\%), including five (16\%) complete responses (CR) and twelve (39\%) partial responses (PR). Twenty-three patients (74\%) showed clinical benefit, i.e. responding and stable patients (CR, PR and NC) maintaining the same status for at least six months (Table 2). The mean overall survival time was 40.8 months (SD 23.8).

\subsection{Quality of life}

Of the 35 Finnish-speaking patients originally in the epirubicin-docetaxel study, four patients had to be excluded: baseline data were missing for two patients, one patient filled in the baseline questionnaire one day after the first cycle instead of on the recommended date, and one patient was non-evaluable for response and was therefore excluded. Thirty-one patients filled in the questionnaire at baseline before the first cycle, twentyfour just before the second, and twenty-five before the eighth cycle. Because only seven patients filled in the questionnaire at the control visit three months after the treatment, it was decided to leave this last visit out of the analysis. The patients whose disease progressed (4 patients) did not fill in the questionnaires at the last cycle as they did not attend the last visits either.

The results from the quality of life questionnaires are 
Table 1. Patient characteristics.

\begin{tabular}{lll}
\hline & N & $\%$ \\
\hline Number of patients & 31 & \\
Age (mean) & 50 & \\
-Range & $35-72$ & \\
Performance status (WHO), mean & 1 & \\
-Range & $0-2$ & \\
Prior treatment & & \\
-CMF & 19 & 61 \\
-CEF & 1 & 3 \\
-Antiestrogen & 6 & 19 \\
Postoperative radiotherapy & 24 & 77 \\
Number of metastatic organs & & \\
involved & & \\
-1 & 14 & 45 \\
-2 & 12 & 39 \\
-3 & 5 & 16 \\
Disease sites & & \\
-Bone & 17 & 55 \\
-Liver & 9 & 29 \\
-Lungs & 15 & 48 \\
Receptors & & \\
-Er+/Pr+, Er+/Pr- or Er-/Pr+ & 22 & 71 \\
-Er-/Pr- & 9 & 29 \\
Number of epirubicin-docetaxel & & \\
cycles & & 87 \\
8 & 27 & 3 \\
6-7 & 1 & 10 \\
3-4 & 3 & \\
\hline
\end{tabular}

Table 2. Clinical response and clinical benefit.

\begin{tabular}{lllc}
\hline Clinical response & N & $\%$ & Stable for at least. 6 months \\
\hline Complete response & 5 & 16 & 5 \\
Partial response & 12 & 39 & 9 \\
Stable disease & 10 & 32 & 9 \\
Progressive disease & 4 & 13 & \\
Clinical benefit no./ \% & & & $23 / 74 \%$ \\
\hline
\end{tabular}

shown in Tables 3-5. Comparison of mean scores of EORTC QLQ-C30 function scales and the global quality of life scale at baseline, prior to the $2^{\text {nd }}$ and $8^{\text {th }}$ cycle are shown in Table 3. The statistically and clinically significant changes were as follows: after the first cycle the emotional functioning improved a little (change of mean by 7.7 points), the physical functioning decreased slightly after the first cycle (8 points), and the cognitive functioning decreased slightly as well (6.7 points). The global quality of life remained unchanged. The mean scores of EORTC QLQ-C30 symptom scales are shown in Table 4. There were no both statistically and clinically significant changes, although there was a trend towards increased fatigue. Table 5 shows the compare-son of mean scores of EORTC QLQ-BR23 breast cancer items during the treatment. A few statistically and clinically significant changes were observed. The concerns about the future were modestly relieved (change of 17 points), while distress related to body image increased modestly (16.1 points). Systemic therapy adverse effects, such as eye and mouth symptoms, head-
Table 3. Comparison of mean scores of EORTC QLQ-C30 function scales at baseline, and prior to the $2^{\text {nd }}$ and $8^{\text {th }}$ cycle. Standard deviations are in parentheses.

\begin{tabular}{lllll}
\hline $\begin{array}{l}\text { Function } \\
\text { scales }\end{array}$ & $\begin{array}{l}\text { Baseline } \\
\text { Mean (SD) }\end{array}$ & $\begin{array}{l}\text { Prior to } 2^{\text {nd }} \text { cycle } \\
\text { Mean (SD) }\end{array}$ & $\begin{array}{l}\text { Prior to } 8^{\text {th }} \text { cycle } \\
\text { Mean (SD) }\end{array}$ & $\begin{array}{l}P \text {-value } \\
1 .-2 \text {. cycle } \\
1 .-8 \text {. cycle } \\
2 .-8 . \text { cycle }\end{array}$ \\
\hline Physical & $79.3(27.5)$ & $71.3(26.9)$ & $72.7(21.0)$ & $\begin{array}{l}0.046^{*} \\
0.14 \\
\end{array}$ \\
& & & & 0.96 \\
Role & $76.9(15.4)$ & $73.9(27.4)$ & $81.3(23.2)$ & 0.36 \\
& & & & 0.87 \\
& & & & 0.30 \\
Cognitive & $91.4(15.4)$ & $93.8(11.8)$ & $84.7(19.6)$ & 0.27 \\
& & & & $0.039^{*}$ \\
& & & & $0.0012^{*}$ \\
Emo- & $71.8(21.1)$ & $79.5(18.1)$ & $78.7(19.8)$ & $0.0018^{*}$ \\
tional & & & & 0.25 \\
& & & & 0.10 \\
Social & $83.3(24.3)$ & $74.3(25.5)$ & $78.7(22.8)$ & 0.11 \\
& & & & 0.30 \\
& & & & 0.70 \\
Global & $68.1(19.1)$ & $64.3(20.3)$ & $68.6(19.5)$ & 0.47 \\
QoL & & & & 0.78 \\
& & & & 0.73 \\
\hline
\end{tabular}

Higher score means better functioning, scale $0-100 .{ }^{*}$ statistically significant difference.

ache and menopausal symptoms, increased significantly (22 points) especially at the beginning of the treatment, and similar changes could be seen throughout the treatment regimen. Distress related to hair loss increased significantly by 75 points.

\section{Discussion}

The combination of epirubicin and docetaxel provided a high degree of clinical benefit with manageable adverse effects in first-line chemotherapy of metastatic breast cancer without compromising global quality of life during the treatment.

During the treatment some positive effects were observed in the quality of life. Anxiety about the future decreased and emotional functioning also improved. This finding of improved emotional functioning after the start of the treatment is in line with previous studies assessing the quality of life with anthracycline and taxane combinations in metastatic breast cancer $[3,8]$. According to Ramirez et al., the improvement in emotional functioning might merely reflect the fact that in a life-threatening situation something was being done, irrespective of what it was, and thus it could simply be an indication of hope [19].

During the treatment, the quality of life declined due to systemic chemotherapy adverse effects. In addition, the quality of life also declined in terms of physical functioning, distress related to body image, and upset 
Table 4. Comparison of mean scores of EORTC QLQ-C30 symptom scales at baseline, and prior to the $2^{\text {nd }}$ and $8^{\text {th }}$ cycle. Standard deviations are in parentheses.

\begin{tabular}{|c|c|c|c|c|}
\hline $\begin{array}{l}\text { Symptom } \\
\text { scales/items }\end{array}$ & $\begin{array}{l}\text { Baseline } \\
\text { (SD) }\end{array}$ & $\begin{array}{l}\text { Prior to } 2^{\text {nd }} \\
\text { cycle } \\
\text { Mean (SD) }\end{array}$ & $\begin{array}{l}\text { Prior to } 8^{\text {th }} \\
\text { cycle } \\
\text { Mean (SD) }\end{array}$ & $\begin{array}{l}P \text {-value } \\
1 .-2 . \text { cycle } \\
\text { 1.-8. cycle } \\
\text { 2.-8. cycle }\end{array}$ \\
\hline Fatigue & 24.4 (21.4) & $33.3(21.2)$ & 31.5 (24.4) & $\begin{array}{l}0.064 \\
0.12 \\
0.99\end{array}$ \\
\hline $\begin{array}{l}\text { Nausea and } \\
\text { vomiting }\end{array}$ & $5.9(16.4)$ & $7.6(11.0)$ & 7.3 (21.0) & $\begin{array}{l}0.72 \\
0.73 \\
0.96\end{array}$ \\
\hline Pain & 18.8 (21.4) & 16.0 (18.7) & 14.7 (18.8) & $\begin{array}{l}0.26 \\
0.49 \\
0.82\end{array}$ \\
\hline Dyspnea & $23.0(25.4)$ & $20.8(27.5)$ & $16.0(19.5)$ & $\begin{array}{l}0.17 \\
0.23 \\
0.88\end{array}$ \\
\hline Insomnia & 30.1 (24.9) & $25.0(26.5)$ & 30.7 (33.2) & $\begin{array}{l}0.31 \\
0.94 \\
0.31\end{array}$ \\
\hline Appetite loss & 7.5 (16.6) & 12.5 (16.5) & 10.7 (24.9) & $\begin{array}{l}0.18 \\
0.54 \\
0.52\end{array}$ \\
\hline Constipation & $6.5(13.4)$ & 9.7 (15.5) & 6.7 (16.7) & $\begin{array}{l}0.31 \\
0.98 \\
0.33\end{array}$ \\
\hline Diarrhoea & $4.3(11.4)$ & $11.1(18.8)$ & 6.7 (16.7) & $\begin{array}{l}0.083 \\
0.52 \\
0.32\end{array}$ \\
\hline $\begin{array}{l}\text { Financial } \\
\text { difficulties }\end{array}$ & $12.2(18.5)$ & $15.3(24.0)$ & $12.0(21.3)$ & $\begin{array}{l}0.39 \\
0.99 \\
0.43\end{array}$ \\
\hline
\end{tabular}

Higher score indicates more symptoms, scale 0 - 100.

caused by hair loss, which are in line with the effect of the doxorubicin and paclitaxel combination on the quality of life [3]. Moreover, the cognitive functioning declined slightly. Subjective cognitive functioning and objective tests measuring cognitive functioning do not always correlate. Subjective cognitive decline often correlates with anxiety, depression or fatigue [20,21]. However, true decline in cognitive functioning is possible as emerging evidence indicates that cognitive changes can be associated with chemotherapy, at least in an adjuvant setting [22]. The negative changes in quality of life in this study could be observed throughout the treatment. However, the negative changes did not adversely influence the global quality of life. Nor have other studies assessing the quality of life with other anthracycline and taxane combinations shown any signifycant change in the overall quality of life. This may reflect the difficulties encountered with data collection and interpretation [2]. In addition, in the majority of metastatic breast cancer studies, despite the different toxicity
Table 5. Comparison of mean scores of EORTC QLQ-BR23 breast cancer items at baseline, and prior to the $2^{\text {nd }}$ and $8^{\text {th }}$ cycle. Standard deviations are in parentheses.

\begin{tabular}{|c|c|c|c|c|}
\hline $\begin{array}{l}\text { Functional } \\
\text { scales/items 1) }\end{array}$ & $\begin{array}{l}\text { Baseline } \\
\text { Mean (SD) }\end{array}$ & $\begin{array}{l}\text { Cycle } 2 \\
\text { Mean (SD) }\end{array}$ & $\begin{array}{l}\text { Cycle } 8 \\
\text { Mean (SD) }\end{array}$ & $\begin{array}{l}P \text {-value } \\
1 .-2 \text {. cycle } \\
\text { 1.-8. cycle } \\
\text { 2.-8. cycle }\end{array}$ \\
\hline Body image & $68.1(22.9)$ & $58.3(28.1)$ & $52.0(30.6)$ & $\begin{array}{l}0.044^{*} \\
0.0026^{*} \\
0.079\end{array}$ \\
\hline $\begin{array}{l}\text { Sexual } \\
\text { functioning }\end{array}$ & $24.4(20.4)$ & $22.5(18.5)$ & $21.7(22.7)$ & $\begin{array}{l}0.84 \\
0.55 \\
0.63\end{array}$ \\
\hline $\begin{array}{l}\text { Sexual } \\
\text { enjoyment }\end{array}$ & $53.8(21.7)$ & 48.5 (34.5) & $42.4(26.2)$ & $\begin{array}{l}0.47 \\
0.36 \\
0.72\end{array}$ \\
\hline $\begin{array}{l}\text { Future } \\
\text { perspective }\end{array}$ & $24.7(25.8)$ & 41.7 (26.5) & $36.0(27.1)$ & $\begin{array}{l}0.0006^{*} \\
0.091 \\
0.15\end{array}$ \\
\hline \multicolumn{5}{|l|}{$\begin{array}{l}\text { Symptom } \\
\text { scales/ items 2) }\end{array}$} \\
\hline $\begin{array}{l}\text { Systemic } \\
\text { therapy side } \\
\text { effects }\end{array}$ & $13.0(7.5)$ & $35.0(12.1)$ & $29.2(15.1)$ & $\begin{array}{l}<0.0001^{*} \\
<0.0001^{*} \\
0.067\end{array}$ \\
\hline $\begin{array}{l}\text { Upset by } \\
\text { hair loss }\end{array}$ & $25.0(16.7)$ & $68.1(30.6)$ & $100.0(0)$ & $\begin{array}{l}0.047^{*} \\
0.017^{*} \\
0.15\end{array}$ \\
\hline $\begin{array}{l}\text { Breast } \\
\text { symptoms }\end{array}$ & $8.0(8.2)$ & $6.9(9.1)$ & $6.3(9.4)$ & $\begin{array}{l}0.047 * \\
0.27 \\
0.56\end{array}$ \\
\hline Arm symptoms & $11.9(12.4)$ & $11.1(13.9)$ & $16.0(14.7)$ & $\begin{array}{l}0.95 \\
0.18 \\
0.14\end{array}$ \\
\hline
\end{tabular}

*statistically significant difference; 1) higher score indicates better functioning; 2) higher score indicates more symptoms.

profiles of the chemotherapeutic agents, only minor or no differences among the different treatment groups have been reported in terms of quality of life [23-25]. It has been reported that physical functioning and treatment toxicity explain only $16 \%$ of the variance in global quality of life, perhaps mostly due to the psychic work that patients are forced to apply to the sense of hope that the treatment offers [26]. Therefore, it can be concluded that treatment-related adverse effects do not usually significantly impair the global quality of life.

Previously, Yeo et al. have assessed the quality of life of Chinese metastatic breast cancer patients during six cycles of an epirubicin-docetaxel combination treatment, after which responding patients received an additional three cycles of docetaxel [9]. They assessed the quality of life using a linear analogue self-assessment scale on nine indices in three major aspects: emotional, physical, and selected symptoms. Yeo et al. reported deterioration of quality of life in all three aspects after the third cycle of chemotherapy, after which there appeared to be 
some improvement. However, the quality of life did not return to baseline level although there was a trend towards improved emotional functioning at the end of the treatment. Our assessment was more comprehensive and detailed using validated quality of life questionnaires. Due to the differences in the methods, it is somewhat difficult to compare the results between the studies. In terms of physical functioning, our results are quite similar, but we found no statistically significant changes in terms of pain, nausea or appetite. The results concerning emotional functioning were different during the chemotherapy. Nevertheless, in both studies, there was a trend towards better emotional functioning at the end of the treatment.

The major limitation of our quality of life study, in addition to the small sample size, is the number of missing questionnaires. The most common reasons for missing data were progressive disease (four patients) and administrative factors such as incomplete collection of questionnaires. In the literature, many other authors have shown that institutional and administrative factors tend to be more influential than patient factors at least until performance status deteriorates $[3,27,28]$. The dropout of the patients with progressive disease is of major concern because it distorts the results. The number of dropouts overestimates the effect of therapy on quality of life as patients with progressive disease and poor performance tolerated treatments poorly. Missing data form one of the greatest methodological challenges in cancer quality of life research [29].

In conclusion, the combination of epirubicin and docetaxel showed clinical benefit among a good number of patients in first-line chemotherapy of metastatic breast cancer with manageable adverse effects. During the treatment the emotional functioning improved and concerns about the future were relieved. Some aspects of quality of life were impaired, with slightly decreased physical and cognitive functioning, distress related to changes in body image and hair loss, and other adverse effects of chemotherapy. However, the global quality of life was maintained.

\section{REFERENCES}

[1] N. Wilcken and R. Dear, "Chemotherapy in Metastatic Breast Cancer: A Summary of All Randomised Trials Reported 2000-2007," European Journal of Cancer, Vol. 44, No. 15, 2008, pp. 2218-2225. doi:10.1016/j.ejca.2008.07.019

[2] D. Ghersi, N. Wilcken and R. J. Simes, "A Systematic Review of Taxane-Containing Regimens for Metastatic Breast Cancer,” British Journal of Cancer, Vol. 93, No. 3, 2005, pp. 293-301. doi:10.1038/sj.bjc.6602680

[3] A. Bottomley, L. Biganzoli, T. Cufer, et al., "Randomized,
Controlled Trial Investigating Short-Term Health-Related Quality of Life with Doxorubicin and Paclitaxel versus Doxorubicin and Cyclophosphamide as First-Line Chemotherapy in Patients with Metastatic Breast Cancer: European Organization for Research and Treatment of Cancer Breast Cancer Group, Investigational Drug Branch for Breast Cancer and the New Drug Development Group Study,” Journal of Clinical Oncology, Vol. 22, No. 13, 2004, pp. 2576-2586. doi:10.1200/JCO.2004.02.037

[4] P. A. Cassier, S. Chabaud, V. Trillet-Lenoir, et al., “A Phase-III Trial of Doxorubicin and Docetaxel versus Doxorubicin and Paclitaxel in Metastatic Breast Cancer: Results of the ERASME 3 Study," Breast Cancer Research and Treatment, Vol. 109, No. 2, 2008, pp. 343350. doi:10.1007/s10549-007-9651-3

[5] J. M. Nabholtz, C. Falkson, D. Campo, et al., "Docetaxel and Doxorubicin Compared with Doxorubicin and Cyclophosphamide as First-Line Chemotherapy for Metastatic Breast Cancer: Results of a Randomized, Multicenter, Phase III Trial,” Journal of Clinical Oncology, Vol. 21, No. 6, 2003, pp. 968-975. doi:10.1200/JCO.2003.04.040

[6] J. Jassem, T. Pienkowski, A. Pluzanska, et al., "Doxorubicin and Paclitaxel versus Fluorouracil, Doxorubicin and Cyclophosphamide as First-Line Therapy for Women with Metastatic Breast Cancer: Final Results of a Randomized Phase III Multicenter Trial,” Journal of Clinical Oncology, Vol. 19, No. 6, 2001, pp. 1707-1715.

[7] G. W. Sledge, D. Neuberg, P. Bernardo, et al., "Phase III Trial of Doxorubicin, Paclitaxel, and the Combination of Doxorubicin and Paclitaxel as Front-Line Chemotherapy for Metastatic Breast Cancer: An Intergroup Trial (E1193)," Journal of Clinical Oncology, Vol. 21, No. 4, 2003, pp. 588-592. doi:10.1200/JCO.2003.08.013

[8] H. Svensson, Z. Einbeigi, H. Johansson, T. Hatschek and Y. Brandberg, "Quality of Life in Women with Metastatic Breast Cancer during 9 Months after Randomization in the TEX Trial (Epirubicin and Paclitaxel w/o Capecitabine)," Breast Cancer Research and Treatment, Vol. 123, No. 3, 2010, pp. 785-793. doi:10.1007/s10549-010-1084-8

[9] W. Yeo, T. S. Mok, K. K. Tse, et al., "Phase II Study of Docetaxel and Epirubicin in Chinese Patients with Metastatic Breast Cancer,” Anticancer Drugs, Vol. 13, No. 6, 2002, pp. 655-662. doi:10.1097/00001813-200207000-00013

[10] J. Korpela and E. Salminen, "Neutropenic Infections Add Significant Costs to Palliative Chemotherapy in Breast Cancer,” Anticancer Research, Vol. 22, No. 2B, 2002, pp. 1337-1340.

[11] E. Salminen, J. Korpela, M. Varpula, et al., "Epirubicin/Docetaxel Regimen in Progressive Breast Cancer-A Phase II Study,” Anticancer Drugs, Vol. 13, No. 9, 2002, pp. 925-929. doi:10.1097/00001813-200210000-00004

[12] E. Salminen, K. Syvanen, J. Korpela, et al., "Docetaxel with Epirubicin-Investigations on Cardiac Safety,” Anticancer Drugs, Vol. 14, No. 1, 2003, pp. 73-77. doi:10.1097/00001813-200301000-00010 
[13] V. Dieras, "Review of Docetaxel/Doxorubicin Combination in Metastatic Breast Cancer," Oncology (Williston Park), Vol. 11, No. 8, 1997, pp. 31-33.

[14] E. Salminen, M. Bergman, S. Huhtala and E. Ekholm, "Docetaxel: Standard Recommended Dose of 100 $\mathrm{mg} / \mathrm{m}(2)$ is Effective But not Feasible for Some Metastatic Breast Cancer Patients Heavily Pretreated with Chemotherapy-A Phase II Single-Center Study," Journal of Clinical Oncology, Vol. 17, No. 4, 1999, pp. 1127-31.

[15] A. B. Miller, B. Hoogstraten, M. Staquet and A. Winkler, "Reporting Results of Cancer Treatment," Cancer, Vol. 47, No. 1, pp. 207-214. doi:10.1002/1097-0142(19810101)47:1<207::AID-CNCR 2820470134>3.0.CO;2-6

[16] N. K. Aaronson, S. Ahmedzai, B. Bergman, et al., "The European Organization for Research and Treatment of Cancer QLQ-C30: A Quality-of-Life Instrument for Use in International Clinical Trials in Oncology," Journal of the National Cancer Institute, Vol. 85, No. 5, 1993, pp. 365-376. doi:10.1093/jnci/85.5.365

[17] M. A. Sprangers, M. Groenvold, J. I. Arraras, et al., "The European Organization for Research and Treatment of Cancer Breast Cancer-Specific Quality-of-Life Questionnaire Module: First Results from a Three-Country Field Study," Journal of Clinical Oncology, Vol. 14, No. 10, 1996, pp. 2756-2768.

[18] D. Osoba, G. Rodrigues, J. Myles, B. Zee and J. Pater, "Interpreting the Significance of Changes in Health-Related Quality-of-Life Scores,” Journal of Clinical Oncology, Vol. 16, No. 1, 1998, pp. 139-144.

[19] A. J. Ramirez, K. E. Towlson, M. S. Leaning, M. A. Richards and R. D. Rubens, "Do Patients with Advanced Breast Cancer Benefit from Chemotherapy?” British Journal of Cancer, Vol. 78, No. 11, 1998, pp. 1488-1494. doi:10.1038/bjc.1998.711

[20] F. S. van Dam, S. B. Schagen, M. J. Muller, et al., "Impairment of Cognitive Function in Women Receiving Adjuvant Treatment for High-Risk Breast Cancer: HighDose versus Standard-Dose Chemotherapy," Journal of the National Cancer Institute, Vol. 90, No. 3, 1998, pp. 210-218. doi:10.1093/jnci/90.3.210

[21] S. A. Castellon, P. A. Ganz, J. E. Bower, L. Petersen, L. Abraham and G. A. Greendale, "Neurocognitive Performance in Breast Cancer Survivors Exposed to Adjuvant Chemotherapy and Tamoxifen,” Journal of Clinical and Experimental Neuropsychology, Vol. 26, No. 7, 2004, pp. 955-969. doi:10.1080/13803390490510905
[22] J. Vardy, J. S. Wefel, T. Ahles, I. F. Tannock and S. B. Schagen, "Cancer and Cancer-Therapy Related Cognitive Dysfunction: An International Perspective from the Venice Cognitive Workshop,” Annals of Oncology, Vol. 19, No. 4, 2008, pp. 623-629. doi:10.1093/annonc/mdm500

[23] L. Hakamies-Blomqvist, M. Luoma, J. Sjostrom, et al., "Quality of Life in Patients with Metastatic Breast Cancer Receiving Either Docetaxel or Sequential Methotrexate and 5-Fluorouracil. A Multicentre Randomised Phase III Trial by the Scandinavian Breast Group,” European Journal of Cancer, Vol. 36, No. 11, 2000, pp. 1411-1417. doi:10.1016/S0959-8049(00)00126-X

[24] A. Bottomley and P. Therasse, "Quality of Life in Patients Undergoing Systemic Therapy for Advanced Breast Cancer,” The Lancet Oncology, Vol. 3, No. 10, 2002, pp. 620-628. doi:10.1016/S1470-2045(02)00876-8

[25] G. Fountzilas, U. Dafni, M. A. Dimopoulos, et al., “A Randomized Phase III Study Comparing Three Anthracycline-Free Taxane-Based Regimens, as First Line Chemotherapy, in Metastatic Breast Cancer: A Hellenic Cooperative Oncology Group Study," Breast Cancer Research and Treatment, Vol. 115, No. 1, 2009, pp. 87-99. doi:10.1007/s10549-008-0047-9

[26] L. Hakamies-Blomqvist, M. L. Luoma, J. Sjostrom, et al.,"Timing of Quality of Life (QoL) Assessments as a Source of Error in Oncological Trials," Journal of Advanced Nursing, Vol. 35, No. 5, 2001, pp. 709-716. doi:10.1046/j.1365-2648.2001.01903.x

[27] P. Hopwood, A. Harvey, J. Davies, et al., "Survey of the Administration of Quality of Life (QL) Questionnaires in Three Multicentre Randomised Trials in Cancer. The Medical Research Council Lung Cancer Working Party the CHART Steering Committee," European Journal of Cancer, Vol. 34, No. 1, 1998, pp. 49-57. doi:10.1016/S0959-8049(97)00347-X

[28] P. Hopwood, R. J. Stephens and D. Machin. "Approaches to the Analysis of Quality of Life Data: Experiences Gained from a Medical Research Council Lung Cancer Working Party Palliative Chemotherapy Trial," Quality of Life Research, Vol 3, No. 5, 1994, pp. 339-352. doi:10.1007/BF00451726

[29] C. C. Gotay, J. Lipscomb and C. F. Snyder, "Reflections on Findings of the Cancer Outcomes Measurement Working Group: Moving to the Next Phase," Journal of the National Cancer Institute, Vol. 97, No. 21, 2005, pp. 1568-1574. doi:10.1093/jnci/dji337 